\title{
Education As an Instrument for an Active Social Policy: Assumptions, Performance, and Prospects
}

\author{
Lucyna Prorok \\ University of Lodz, Lodz, Poland
}

\begin{abstract}
The crisis of the welfare state caused the change of the approach to the policy of social protection and the tools of its realization in countries of EU. The present trend consists in the transfer of the responsibility for the welfare of the society from the state to local autonomies, businessmen, and, first of all, people themselves. A basic assignment of the present social policy is building active attitudes of persons and families being found in a difficult situation. Help in this has to be: the realization of the watchword work instead of benefit and the broadly understood education as the protection (guarantee) against life risks. Therefore, the author undertook synthesis of the current sociological knowledge on the change of an approach to social policy objectives formulation. Using qualitative methods, she analyzed the content of literature comprising (showing) discourses on the opportunities and constraints associated with the modernization of the existing social policy and selected EU documents.
\end{abstract}

Keywords: active social policy, activity, social policy, social inclusion, education, educate

\section{Introduction}

Not only does the commonly observe crisis of the welfare state, but also the global economic crisis brings about changes in approach to the policy of social security and the social policy accomplishment. In short, it can be said that the present trend consists in the transfer of responsibility for people and society's prosperity from the state to the social policy actors being less engaged so far, such as social groups, businessmen, local governments, and above all, individuals. This kind of action is performed according to the saying "As you make your bed, so you must lie on it", whereas the action of making your bed is taking care of one's own business, self-help, predictability, long-term thinking, and especially paid work that allows one to gain. It may seem to be obvious, and even necessary, and results directly from broadly understood progress.

However, there is one question: If such a change is for everyone? After all, each society has its so-called weaker individuals or the whole groups that are disabled somehow or they have limited abilities to self-create their own welfare. According to theorists and reformers, there is a place in this area for the active social policy as a remedy to crises in lives of individuals who have lived at the cost of the welfare state being the dregs of society so far. In this sense, the active social policy is understood as a strategy of supporting and/or persuading people to be active in many important for the society roles, i.e. professional, educational, and many others (Grewiński, Karwacki, \& Rymsza, 2010).

Lucyna Prorok, Ph.D., assistant professor at the Department of Sociology of Education, University of Lodz, Lodz, Poland.

Correspondence concerning this article should be addressed to Lucyna Prorok, Department of Sociology of Education, University of Lodz, ul. Rewolucji 1905 r. 41/43, 90-255 Lodz, Poland. E-mail: lucpro@wp.pl. 
The above-mentioned approach assumes that one of the main functions of a social help is to build active attitudes among people and families that are in a difficult situation. Furthermore, it is important to restore the meaning of "work" in person's life as being the value which gives freedom and ability to self-determination (work ethos, through work to freedom). Undertaking of the action for increase in a level of a person's employment demands a number of activities connected with education, psychosocial rehabilitation, sociotherapy, and etc., therefore, the following issue emerges as the problem question to the author: Can education replace a system of social welfare benefits by becoming an instrument for the active social policy? The aim of the analyses will be to explain how acquiring of the knowledge and abilities allowing learners to enter and remain on the contemporary labor market should be proceeded.

\section{Instruments of Active Social Policy}

The idea of the active social policy involves encouraging individuals with specific socio-economic characteristics to undertake activities in a variety of important and necessary roles from a social point of view (Szarfenberg, 2007). Furthermore, it is to increase the proportion of professionally active people, which in a market economy is a measure of economic success and progress of civilization. Then, it is reasonable to move away from the social policy focusing mainly on the provision of benefits in cash (passive actions), and to introduce actions on motivating people to social, professional, and economic activity, called activation measures (Rymsza, 2013). Therefore, "work rather than benefit" is a watchword in the social policy of the 21 st century, resulting from a number of conditions, such as the global economic crisis and the crisis of the welfare state, as well as the realization of the right to work for all.

As it is known, the scope, nature, and expected effectiveness of the social policy instruments depends on whether people deal with explicit or implicit policy. On this basis, a catalog of benefits is being created, so that it can be used by different social groups with different financial status, having different needs, but also the possibilities. Instruments of a typical social policy may thus be classified according to their forms, which are:

- legal norms - that govern the rights and obligations of individual members of society, define the criteria and rules for the social benefits granting (cash, property, and services), and classify beneficiaries, e.g., law, legal acts;

- cash - which, depending on the type of benefits, is obligatory (family, maternity, and education allowances) or discretionary (social assistance, scholarships);

- benefits in kind - any kind of help that a person can get due to their difficult financial situation, e.g., food, clothing, rehabilitation equipment, and consultations with specialists (legal or medical advice, vocational guidance);

- social services-so-called social infrastructure (private or public) which is used by a different range of social assistance beneficiaries, e.g. institutions of education, health care, culture, and etc..

Some authors (Rysz-Kowalczyk, 2001; Firlit-Fesnak \& Szylko-Skoczny, 2007) applied the division of the social policy instruments, due to the nature of the needs of potential beneficiaries being satisfied, such as the need for social security, unemployment prevention, education, and upbringing. Moreover, the social policy is classified according to the criterion of efficiency of benefits for beneficiaries, therefore regardless of whether the aid is financial or in-kind, the benefits may all serve one or more of the following functions simultaneously, i.e.: function of income, compensation, redistribution, egalitarisation, and stimulation. 


\section{Social Policy Instruments and Activation}

In the case of the active social policy implementation, there are primarily used instruments of labor market policy, which not only activate, but also strengthen the current professional situation of individuals benefiting from the support. In terms of the active instruments, the following can be recognized as the most commonly used: public employment services (job placement and vocational guidance together with the costs of administration); vocational training; job rotation and division of labor; the employment incentives (programs to employ the unemployed or maintaining a workplace that without the support would be liquidated); promote the employability of the unemployed and rehabilitation of persons with disabilities; and direct job creation and support for making business. Furthermore, statistics and studies of European Statistical Office and Organization for Economic Co-operation and Development distinguish passive instruments such as allowances and severance benefits for the unemployed and early retirement. They are treated as a last resort, especially since it is dealing with a Europe-wide trend to extend working lives of people.

The above-described benefits and social services may be addressed to all (universal) or some (selective). An example of the universal service is a free access to education. Teaching children and youth at all levels of education is free in most European countries, except the UK, where a college is paid for. Social assistance benefits are selective in all countries. The availability of these is dependent on the fulfillment of certain conditions that are checked (means-tested). Since the 90s of the 20th century, the tendency to replace the services previously offered according to universal rules with the services being selectively offered has been observed. This involves the belief that specific people should receive help deliberately and the resources should not be wasted on actions which do not bring the expected results. Thus, for example, instead of training for the unemployed, some of them are offered self-employment within the development of micro-enterprise (Szarfenberg, 2007).

\section{Critical Analysis of Social Policy Methods}

As regards the social policy, it has been criticized by skeptics who believe that in the current unstable economic situation, it is difficult for inexperienced people to develop their own business ventures. Moreover, as noted by Golinowska (2002), a selective approach to the social benefits has fundamental disadvantages which place into question its usefulness, and they are: higher administrative costs associated with running the system, stigmatization on recipients of benefits, and the effect of reducing the motivation for their own professional activity. Besides, the organizational problem, even more a socio-cultural one, is an issue of persuading people with small chances for finding work to feel the need of finding employment or undertaking any activity. Therefore, activities for people at risk (people with disabilities, long-term unemployed, the homeless, addicts, mentally ill, ex-offenders, refugees), in addition to vocational training, should include elements of interpersonal training that would develop a positive attitude towards work. From this point of view, education in the active social policy, as its principal instrument, should primarily serve two functions:

- stimulation-involving the creation of desired attitudes or public consumption direction deemed valid for the general public;

- egalitarisation - which is to level differences in the standard of living of different social groups.

\section{Education as an Instrument of the Active Social Policy}

The background for the implementation of the social function of education is the systematic development of 
the knowledge economy, which motivates to increase qualifications, learn new skills, and use various forms of education. In addition, the increase in the importance of education and knowledge being acquired can be associated with better earnings, stimulate stronger citizenship, and make it easier to overcome social inequalities. Therefore, back to the question "can education replace a system of the social welfare benefits by becoming an instrument for the active social policy that is available for each individual", the author refers to the European model of education as the main pattern to be followed and realized in the Polish reality.

\section{Creating Quality of Human Resources}

For the socio-economic growth across the whole European Union, a vital issue is the quality of human resources understood as social capital which depends on, among others, the education system in which the transfer of cultural heritage, knowledge, skills, and system of values in the community occurs (Socha-Sachalin, 2000). Therefore, the strategic documents of the European Union (Lisbon Strategy) underline the importance of the principle of educational opportunities equality, through which it becomes possible to implement the principle of social inclusion which is the foundation of the active social policy. The above-mentioned equality of educational opportunities is implemented through such structuring of educational systems that would relate to all children and young people, regardless of their ethnic and cultural origin, place of residence, socio-economic status, or health status (Retrieved from http://www.europarl.europa.eu/sides/getDoc.do?pubRef=-//EP). In this sense, the education also serves as preventing a possible social dysfunction in adulthood of children and young people, as early initiation of the educational activity in the future will be translated into their professional activity.

Activating actions of education also mean making it possible to gain knowledge and qualifications by disabled people, so that within their abilities, they could function independently, satisfy their needs, and participate in all spheres of socio-economic life of the country (Godlewska \& Jaroszewska, 2007). This approach results from the observation of labor market reality, which through the evolution of the various forms of employment gives a chance of working to everyone (who is willing). Another matter is education and upbringing as the fight against any symptoms of discrimination, especially the one against women and elderly persons, in the labor market and access to the public life, markets of services and goods, culture, education, recreation, and etc.. The education in this sense acts as the egalitarisation, giving the opportunity for independence and self-fulfillment to people of all ages, sexes, and family situation. The implementation of a social integration principle as well as eliminating the discrimination through the education, in this sense is associated with the promotion of active aging of population and solving social problems of people who are at a disadvantage on the labor market.

\section{Unification of Education Programs}

The education can serve as an instrument of the active social policy, if there is a unification of education programs within the European Union in order to make the skills, knowledge, and qualifications comparable across each country. This is particularly important in the case of the opening of labor markets and the free movement of workers. The second of the EU education policy priorities aims to serve this need, and it is the one that is related to improve the quality of the education policy at different levels of education and to the different expectations of its addressees (Retrieved from http://www.europarl.europa.eu/sides/getDoc.do?pubRef=-//EP). Generally, the improvement in the quality of education is realized through: 
- adaptation of learning content to the needs of the European labor market;

- departure from encyclopedic and general learning, and implementing knowledge of creative problem solving and linking theory with practice, especially at higher levels of education;

- use of modern technology in the process of education according to predispositions, skills, and level of the students;

- differentiation of rate of knowledge acquisition by the students, according to their intellectual level and the type of personality and ability to learn;

- last issue concerns people already existing on the labor market, for whom relevant changes should be implemented in accordance with the their needs, and these are changes to vocational guidance, vocational training, and programs that enhance the opportunity to gain new employment or change professional qualifications.

Unfortunately, in the Polish reality, realization of the noble objectives encounters problems associated with different levels of educational services. It is a question of the division into urban and rural schools where students have different opportunities to develop their skills, passions, and interests. In addition, extracurricular education is definitely at a higher level (wide range) in large urban areas, both for children and youth, as well as for adults. Another problem of the education system is the losing of talented individuals, because both schools and teachers have limited opportunities to individually educate people that are much more talented than the others.

As regards obtaining a job, realization of the priority to improve the quality of education should put emphasis on vocational training to protect young people from unemployment. Through the professional work, one continues one's education, develops socially, and acquires new roles, and its absence causes economic and social poverty, as well as creates a dysfunctional personality. People, who have never worked (or only short), did not acquire professional habits and ability to functioning in a task group, did not have developed a sense of duty or responsibility, and etc.. That is why unemployment among young people is not only a matter of economic exclusion, but also a competence-cultural one, therefore, improving the quality of education should substantially leads to:

- providing students with knowledge that guarantees employment and participation in the labor market;

- developing interests based on skills that are already possessed or development of new ones;

- developing life capital of children and youth;

- developing a wide range of education for adult (working);

- teaching how to learn as well as developing skills associated with the (independent) problem solving (Publications Office of the European Union, 2014).

\section{New Model of Teaching}

The suggested new model of teaching in the contemporary European educational policy is an extension of the previous priority. It covers issues related to the organization of the education system at secondary and higher levels. The basic emphasis here is placed on soft skills, i.e., on teaching the youth creative and innovative attitudes to life that would enable them to find their place in the European social structure and on the labor market. Another important element in the new model of educating is the creation of human capital responsible for the development of the European knowledge-based economy. This involves the treatment of knowledge (specialized 
mainly) and the ability to create and process information as desired goods in the modern economy. In addition, the aim is to formulate, within the education system, a certain profile of a European who is brought up in a spirit of social, religious, racial, and ethnic tolerance, respects peace, and democracy, speaks foreign languages, and has international contacts and knowledge about the place of the EU in global politics, the economy, and the community. Additionally, the implementation of this assumption is only possible through the continuous improvement of qualifications and verification of school and/or university knowledge, considering the level, development, and state of scientific research in the current resources of the global science.

However, one may have doubts whether such a postulate towards the education policy still realizes the objectives of education itself, for example, in the process of making equal educational opportunities. It is a truism here to say that education costs, especially extracurricular learning of foreign languages or disciplines developing the skills and abilities of children and adolescents. The above-mentioned division into urban and rural schools or available offer of training that depends on the location, makes not only financial issues, but has an impact on the successful life of individuals. It is directly related to further objectives of education, such as the removal of social inequalities and improving the level of culture in people's lives. Although education is one of the ways of investment in the human capital, still in many schools, there is a segregation of students, division into richer and poorer, which is not conducive to achieve the potential benefits and payback in the future (Publications Office of the European Union, 2014).

Furthermore, the above assumptions are part of the so-called European education path that is split into individual school levels, however, people who are already outside the education system are not taken into consideration here. From the point of view of the active social policy idea, this priority is very important, because it prepares young people with responsible acting in society. The people who are already outside the education system also would need support in acquiring competencies allowing them to move freely in the European socio-economic space.

\section{The European Model of Education}

The presented element of the contemporary education policy is the European model of education which involves the formation of various types of so-called soft skills that include social skills, communication, and teaching to learn. It is important to include in the school the academic curricula issues allowing to create, develop, and educate an active, smart, and law-abiding person - the European. The rationale for the realization of this priority is the need to invest in children and adolescents, which is synonymous with the future security and protection against unemployment, social exclusion, poverty, and pathology. This can be understood as an act of prevention rather than later compensation for the effects of unemployment and social exclusion. In this sense, the system of education meets important social functions which include:

- shaping the social structure of certain socially desirable characteristics including level of education, professional position, desire to achieve above-average success and social prestige;

- strengthening the modernization capacity of the particular society;

- adjusting the contents and forms of education to the expectations of employers and the labor market (Buchner-Jeziorska, 2013).

The increased investment in the human capital is also supported by the fact that well-educated individuals easier adapt to changes, therefore, in modern Europe, it is to be presumed that the ability to adapt will be an essential asset of whole societies (Giddens, 2006). It is then assumed that the provision of the life capital for an 
individual is the best guarantee for the security against unfavorable life events, and thus will allow to limit the social function of the state towards its citizens.

\section{Conclusions}

The expectations towards education are mainly due to two issues: (1) the growing educational needs of the contemporary European society and the development of a knowledge-based economy and (2) the education performing a function of stratification (Buchner-Jeziorska, 2013). This all makes that education is a necessity, not a choice in the sense that individuals decide their own socio-economic success or failure through participating in or not in the educational process in such a way and not another.

It is known that no one can be forced to learning or social advancement, but changes occurring in the area of public policies show that more and more responsibility falls on individuals in terms of quality and level of their own lives. A symptom of this is the departure (progressive in individual European countries) from the classic welfare state, and the pursuit of workfare state created together with citizens responsible for their own welfare. Hence, there is an increase in the list of expectations of the European education policy and public education systems, which (as you cannot forget) are determined by various factors:

- social (a state of development of society and the characteristics of the social structure);

- economic (level of economic development, economic expectations of certain types of attitudes, skills, and knowledge);

- political (the vision and the importance of education in EU programs and the ruling party of the country).

The reformist efforts aim at education adopting new socially important functions, as appropriate preparation of future employees ensures their adaptive readiness to changes in the labor market. Therefore, the education, acquisition of competences of learning, self-confidence, and entrepreneurship, can help to reduce the possible risks and future unemployment. The problem is still in the question of students' mentality that is in how to make them active in an educational-professional sense. In this area, there is a variety of activities to activate and reintegrate the society, tailored to the needs and abilities of their beneficiaries. It is also important to awaken public awareness of the benefits of professional activity, that is, the restoration of the work ethos. Only then can people talk about the effectiveness of activation measures, education, and investment in human capital. To finally sum up, this paper can conclude that it is necessary to take further measures at the system-level that would strengthen the role and the importance of education in the life of a modern human, which will allow the social policy to depart from the protective measures for the benefits of the activation ones.

\section{References}

Buchner-Jeziorska, A. (2013). Equal access to higher education in Poland. Based on example of Lodz University. Lodz: University of Lodz Press.

European Parliament, Committee on Culture and Education. (2014). Resolution PE/2004/2272/INI on education as the foundations of the Lisbon process. Retrieved from http://www.europarl.europa.eu/sides/getDoc.do?pubRef=-//EP

Firlit-Fesnak, G., \& Szylko-Skoczny, M. (2007). Social policy: Academic textbook. Warsaw: WN PWN.

Giddens, A. (2006). How to save a social model? The biggest threats. Europe, 137, 11-11.

Godlewska, J., \& Jaroszewska, E. (2007). Education, knowledge and skills: Education, educational policy and guidance. In G. Firlit-Fesnak, \& M. Szylko-Skoczny (Eds.), Social policy: Academic textbook. Warsaw: WN PWN.

Golinowska, S. (2002). Social assistance-Change and the conditions of effective action. Warsaw: CASE.

Grewiński, M., Karwacki, A., \& Rymsza, M. (2010). The new social policy-Activation, multisectorality, and co-decision. Warsaw: Mazovian Center of Social Policy. 
Publications Office of the European Union. (2014). Education, training, youth, and sport. Education and training-The key to your future. Retrieved from http://www.europa.eu/pol/pdf/flipbook/en/education_training_youth_and_sport_en.pdf

Rymsza, M. (2013). Activation in social policy. Towards European welfare states reconstruction? Warsaw: IFiS PAN Publishing. Rysz-Kowalczyk, B. (2001). Lexicon of social policy. Warsaw: ISP UW, ASPRA—Jr Publishing Office.

Socha-Sachalin, S. (2000). The social policy. Koszalin: Publishing of Engineering College in Koszalin.

Szarfenberg, R. (2007). Types and forms of active social policy. In G. Firlit-Fesnak, \& M. Szylko-Skoczny (Eds.), Social policy: Academic textbook. Warsaw: WN PWN. 